\title{
O entendimento de liberdade construído pela imprensa em Minas Gerais e suas variações ao longo do império
}

\author{
Márcio Achtschin Santos
}

\author{
Palavras-chave: \\ Liberdade \\ Imprensa Mineira \\ Brasil-Império
}

Keywords:

Freedom

The Minas Gerais Press

Brazil-Empire

\begin{abstract}
Resumo: Este artigo se propõe a analisar as diversas visões de liberdade feitas pela imprensa mineira ao longo do Império brasileiro. A proposta é buscar através dos periódicos publicados em Minas Gerais os diversos sentidos dados à representação de liberdade, tendo como referência o Primeiro Reinado, o Período Regencial e o Segundo Reinado. Por fim, este trabalho pretende identificar uma elaboração própria para um sentimento de liberdade construído pela imprensa mineira.
\end{abstract}

\begin{abstract}
This article proposes to analyze the different visions of freedom made by the Minas Gerais press throughout the Brazilian Empire. The proposal is to search through the periodicals published in Minas Gerais the various senses given to the representation of freedom, having as reference the First Reign, the Regulative Period and the Second Reign. Finally, this work intends to identify a proper elaboration for a feeling of freedombuilt by the Minas Gerais press.
\end{abstract}

Recebido em 09 de maio de 2017. Aprovado em 07 de agosto de 2017.

\section{Introdução}

Para Lúcia Maria Bastos P. Neves (2001), o sinal mais evidente da chegada da modernidade é o embate entre o Antigo Regime e as Luzes. Neves considera que liberdade tornou-se a palavra central para a cultura política liberal no final do século XVIII e ao longo de todo século XIX. Ressignificando a ideia de liberdade absoluta, a ilustração rocurou aproximar o conceito a aspectos jurídicos, criando a relação direta entre ser livre e a observância das leis. Isso colocava a liberdade como tema central das discussões, especialmente sua aplicação e seus limites, inclusive no Brasil do Oitocentos. Alfredo Bosi (1998) e Gladys Ribeiro (1997) entendem que a construção de uma representação de uma liberdade branca no Brasil, semelhante aos Estados Unidos, apenas foi possível pela existência da escravidão, pois era a contraposição para existir socialmente o branco livre e proprietário, ou seja, somente existiu o branco livre porque havia o contraste da escravidão negra. Sendo assim, segundo Ribeiro, a discussão em torno da liberdade a partir do processo de independência teve como ponto de partida o olhar do proprietário.
Para Lúcia Maria Paschoal Guimarães (2001), a linguagem liberal é abstrata: afinal, não identifica quem é a nação ou os cidadãos, quem pode participar do sistema representativo ou quem elabora as leis. Favorecendo construções difusas e contraditórias, oportunizando o uso de práticas e termos de acordo com contextos históricos e interesses de grupos sociais, o liberalismo assumiu diversas roupagens. Evidentemente, a representação de liberdade também seguia o mesmo grau de variações e adaptações. No caso brasileiro, essa ambiguidade surgiu em diversos momentos ao longo do império, ajustando-se à medida dos interesses de determinados grupos que defendiam ou buscavam conquistar o poder.

Esse debate em torno da liberdade também chegou à província mineira no século XIX, assumindo especificidades regionais. Muito marcada ao longo do século XIX por representações vindas da Corte, dentro de uma pedagogia política de apoio ao império (SILVA, 2009), ou receptora da cultura liberal estrangeira, é fundamental entender que Minas Gerais possuía uma realidade própria, com interesses específicos. Particularidades que demonstravam que nem sempre comungavam

\footnotetext{
* Doutor em História e Cultura Política pela Universidade Federal de Minas Gerais (UFMG), professor do curso de Serviço Social pela Universidade Federal dos Vales do Mucuri e Jequitinhonha (UFVJM).
} 
ou se beneficiavam com o projeto imperial, tendo uma composição de atores de um mundo vivido distinto, ajustados a acordos e conflitos próprios da província.

Assim, a questão levantada nesse trabalho é como a imprensa mineira debatia o tema "liberdade" ao longo do Império e como adequou suas representações a uma realidade própria. Procura analisar nesse contexto como o conceito e os discursos construídos na imprensa acerca da liberdade foram ajustando-se às transformações ocorridas tanto nacionalmente como na província mineira, ganhando contornos próprios em Minas Gerais especialmente na segunda metade do século XIX.

As fontes consultadas on-line são os jornais produzidos na Província de Minas Gerais do século XIX digitalizados pelo Arquivo Público Mineiro em PDF digitalizados pelo Arquivo Público Mineiro tendo como recorte temporal o início da formação do Estado brasileiro até a queda da monarquia. Dividido em quatro seções subcapítulos - a primeira presenta o entendimento da liberdade no Primeiro Reinado. A segunda parte segue em busca de suas permanências e mudanças no Período Regencial. A terceira presenta a construção da representação de liberdade no Segundo Reinado. Por fim, a quarta seção analisa os contornos próprios assumidos pela liberdade na província mineira.

\section{A liberdade exposta na imprensa mineira no Primeiro Reinado}

Quer seja em longos artigos ou curtas citações, a preocupação da imprensa mineira nas primeiras décadas do Dezenove era não só definir, mas também demarcar as ações, estabelecer os limites da liberdade, apropriando-se, para tanto, de pensadores de grande expressão como Constant, Bentham, Montesquieu e Hobbes, ou de menor conhecimento, mas citados exaustivamente como Donoyer ou Lacretille.

Essa defesa da liberdade deveria, segundo a imprensa, ser difundida a todo custo, mas dentro dos princípios da moderação A estratégia adotada como luta simbólica cotidiana acabou por pretender impor uma visão do mundo social que tornasse consenso, não apenas como senso comum, mas também como instrumento político pela moderação. A representação da liberdade estava estreitamente ligada à formação do Estado Imperial, ou seja, rotinizar o tema sobre liberdade implicava em uma aproximação com a ordem. A população de Minas Gerais deveria estar subordinada à recém-criada nação: “[...] trabalhai em comum pela prosperidade da nossa Pátria [...]"1, em comunhão com a ordem e os princípios liberais: "Viva a Constituição. Viva a Liberdade. Estas 2 amigas, que sempre de mãos dadas jamais se separam um só instante, pois que não pode haver Liberdade sem Constituição, nem Constituição sem Liberdade"2.

Coexistindo com o uso rotineiro da expressão liberdade, foram construídos longos editoriais e artigos discutindo o seu sentido e os seus limites, esclarecendo qual o tipo de liberdade poderia ser vivenciado em Minas Gerais e no Brasil. Em alguns momentos, essas produções eram reproduções de publicações da imprensa do Rio de Janeiro e São Paulo (MOREIRA, 2006), fragmentos de obras literárias traduzidas, mas também eram editoriais e artigos escritos pelos mineiros ou correspondências de leitores locais.

$\mathrm{O}$ primeiro desses longos escritos disponíveis foi publicado entre 30 de abril e em 02 de maio de 1827, no jornal liberal "O Universal", que dedicou as suas principais páginas, em três edições, para publicar o "Discurso sobre a liberdade". No artigo, sem identificação de autoria, existe um dos pontos permanentes nos discursos da imprensa quando esta abordava o tema, qual seja a condenação da liberdade que não seja subordinada às leis sociais. Fazia então o contraponto entre a "verdadeira liberdade" (ou "justa liberdade"), fruto da sensatez e racionalidade humana, regulada pela lei e consequência da vida social que o ser humano construiu, e da "liberdade total", esta resultado de um sonho irrealizável, que traria apenas males e deve ser reprimida: "A verdadeira liberdade é a que permite o homem fazer tudo desde que em sociedade e a 
total liberdade é puro sonho, um delírio, devendo por interesse de todos ser reprimida e castigada" 3 .

Jornais de tendências menos liberais e que mantinham apoio incondicional ao governo também colocavam em pauta o tema, reconhecendo ser um assunto na ordem do dia: "Muito se tem falado e escrito sobre a liberdade" ${ }^{4}$. O conservador "O Telégrafo" 5 acreditava que jornais liberais no perfil de "O Universal" e "Astro de Minas" excediam no limite dado à liberdade, chamando estes, em edição de 28 de dezembro de 1830, de "liberalões", acusando-os de defenderem maior autonomia das províncias e de inimigos do trono imperial, sendo seguidores da "[...] seita do iluminismo, fruto de periódicos que defendem a confederação, resultado de uma "liberdade não entendida"'. A liberdade tratada pelo "Amigo da Verdade" também levava em consideração os limites a serem adotados para o seu exercício na vida social. No entanto, diferentemente dos jornais de tendências liberais, os jornais conservadores encontravam muito mais confronto do que aproximação entre liberdade e as leis, conforme expressa esse trecho de 29 de maio de 1829: “[...]Quanto mais dever, menos liberdade. Logo, os deveres estão na razão direta das relações e a liberdade está na razão inversa dos deveres"7.

$\mathrm{Na}$ apresentação da primeira publicação do "O Amigo da Verdade"8 de 08 de Maio de 1829, esse tema foi amplamente discutido no seu editorial, no qual o periódico fazia oposição à liberdade irrestrita da imprensa, entendendo que seu uso abusivo levava a grandes males sociais, principalmente pela fragilidade do que chamava de Opinião Pública. Na visão do periódico há limite para esse tribunal, que seria a manutenção da ordem e do governo imperial constituído. A liberdade de opinião estaria diretamente relacionada com a estabilidade do Império. Ainda segundo " $O$ Amigo da Verdade", o debate livre poderia afastar a razão e estimular a paixão popular, resultando na instabilidade do que era para o jornal a monarquia constitucional representativa brasileira instalada, especialmente em uma população que ainda não tinha instituições sólidas.

Esse debate sobre a liberdade da imprensa no Brasil é um tema que provocou diversas discussões ao longo de todo o I Reinado, especialmente pela ação do governo contra a livre publicação, o que vai reforçar a manutenção do tema sobre liberdade em pauta na imprensa da província. Segundo Kátia Carvalho (1996) houve a substituição da censura prévia existente quando o Brasil era colônia para a esfera jurisdicional. Mas, por falta de uma lei ordinária para regular os excessos após a Constituição de 1824, prevaleceu o Decreto de 22 de novembro de 1823, dando base para que fosse considerado delito as ações que colocassem em risco a segurança interna e a existência política do império e a tranquilidade pública, previsto como punição multas e prisão.

O próprio "O Universal" foi atingido por essas ações feitas às oposições pelo império. Em suplemento de 26 de outubro de 1829 , comemorou a não criminalização do artigo publicado no número 226: "A liberdade de imprensa acaba de obter mais um triunfo, com que contava e contará sempre que os escritos forem baseados sobre os sólidos fundamentos da lei" ${ }^{\prime \prime}$. Não estando disponível nos arquivos para poder saber o conteúdo do referido artigo, o fato é que o risco constante de condenações dos periódicos exigia dos editores alguns artifícios para não serem punidos por crime contra a ordem pública ou contra a política imperial.

Diante das alternativas que tinha o governo de punir opositores, os jornais liberais procuravam debater sobre a liberdade de imprensa usando argumentos de autores ilustrados europeus, artigos de jornais da imprensa do Rio de Janeiro ou editoriais. No caso do Primeiro Reinado, o uso do termo e dos conceitos em relação à liberdade pode sinalizar uma alternativa para fazer resistência à forte perseguição sofrida pela imprensa no governo de D. Pedro I, sendo um tema que tinha o abono dos grandes expoentes das luzes (muitos assinados pelos ilustrados europeus), atingindo de forma indireta os abusos do que os liberais consideravam como déspota e tirano.

$\mathrm{O}$ jornal "O Universal"10 reafirmou, em 03 de dezembro de 1827, as vantagens da liberdade de imprensa contrapondo os prejuízos ocorridos quando esse direito era cerceado. $\mathrm{O}$ artigo responsabilizava os governos autoritários 
pelos abusos cometidos na produção escrita, pois radicalizam os conflitos políticos, concluindo que, como não era a liberdade de imprensa a responsável pela má administração, o governo devia rever seus rumos e procurar reformar suas práticas. Ainda assim, de modo geral eram publicações moderadas, com críticas sutis, quer seja pela pouca proximidade de um discurso mais radical, quer seja pelo temor de sofrer as punições previstas pela lei, ou pior, ter o destino do italiano Líbero Badaró.

\section{A Regência e 0 anarquismo: os excessos da liberdade}

Após a abdicação de D. Pedro I ocorreu um deslocamento dos atores políticos que vão assumir a defesa da liberdade, ou seja, saiu de cena o primeiro imperador, entrou seu filho. Mas o discurso da ordem e da legalidade foi preservado. A saída de D. Pedro representou nas lentes da imprensa a luta do povo brasileiro contra o despotismo, tendo como referência a Constituição e sinalizando para o destino tomado àquele que se opusesse à legalidade. A queda de D. Pedro I deu abertura para críticas mais contundentes. Em 1831 passou a ser apontado como um déspota, "um monarca iludido"11, "um ingrato príncipe ${ }^{12}$, tirano que não soube obedecer aos princípios da liberdade e foi derrubado em nome da pátria e da Constituição, conseguindo "a liberdade vitoriosa calcar aos pés o monstro do despotismo"13.

No entanto, o discurso da imprensa mineira continuou com a tendência de união entre a liberdade e a ordem/legalidade. Naquele momento, no entanto, alinhado com a Regência. Um comunicado encaminhado para a província mineira e publicado em 20 de abril de 1831 no " $O$ Universal" 14 assinado pelos regentes marquês de Caravelas, Nicolau Vergueiro e José Joaquim de Lima e Silva, ritualizava o "07 de abril", considerado como um "triunfo da liberdade", "triunfo da liberdade constitucional" e "vitória incruenta da liberdade".

Na primeira publicação após o "07 de Abril” "O Universal" noticiava a queda de D. Pedro I, fazendo a relação entre a liberdade e a Constituição:
"Vede como a constituição melhorou nossa sorte [...] e que ataca a Constituição pretende golpear vossos direitos [...] não escutai a voz da pátria e da liberdade"15. O primeiro editorial a comentar de forma mais exaustiva a abdicação de D. Pedro I, no "O Universal", ocorreu somente duas semanas depois, procurando relacionar a luta do brasileiro pela liberdade contra o despotismo, onde a retirada do imperador foi em decorrência da não aceitação do povo diante dos abusos do monarca, agindo de modo a superar a força sagrada da lei.

A representação, agora para a preservação dessa conquista, passou a ser D. Pedro II, sendo este considerado o novo baluarte da liberdade no Brasil, especialmente porque o seu berço tinha como referência uma educação fundada nos valores constitucionais, carregando no coração o sentimento de ser livre, perfil típico de quem era da América. De acordo com o jornal "O Universal", de 08 de abril de 1831, a liberdade vivenciada por D. Pedro II fugia à tirania, pois crescia sendo educado com o sistema constitucional ${ }^{16}$. No discurso da imprensa, o dia "07 de abril" foi uma conquista, fato ocorrido em nome da liberdade, que se realizou dentro da legalidade, sem derramamento de sangue, considerado algo inédito na época. Assim, a imprensa trabalhou com a reação brasileira como um modelo a ser copiado pelo mundo: "Que exemplo para os tiranos da Europa, para as nações do Velho Mundo!... vinde povos todos aprender conosco a sustentar a liberdade, a manter os direitos públicos..." ${ }^{17}$.

Os artigos ressaltando a ordem e a legalidade continuaram, mas os primeiros momentos após a saída do imperador motivaram a imprensa moderada a colocar em debate as possibilidades de reformas. Contudo, o temor de agitações que radicalizassem as propostas de mudanças políticas e que começava a se manifestar no Rio de Janeiro e em algumas regiões do Brasil, abrandou o entusiasmo dos primeiros momentos. Há um recrudescimento dessa postura, visto que, dentre outros fatores, foram repensados pela própria imprensa conforme aponta Morel (p. 211, 2005): “[...] diversos redatores liberais começavam a se arrepender do que consideravam 'excessos' de uma opinião politizada que eles ajudaram a criar". A discussão em torno 
do uso e dos limites da liberdade acompanhou esse fluxo, apresentando um risco à ordem por provocar debates fugindo da "verdadeira liberdade" desejada pelos liberais moderados, estimulando a radicalização dos movimentos e questionamentos em torno do uso e dos limites que essa liberdade poderia alcançar. E em 09 de setembro 1831, a preocupação em torno dos excessos de liberdade superou a luta pela ausência dela: "A liberdade não pode marchar sem prudência, nem viver sem virtudes. Mais vezes é destruída a liberdade por seus excessos do que por seus inimigos"18

O resultado desse zelo levou a substituir temas voltados ao temor do despotismo pelo horror da anarquia. Em artigo publicado em 26 de outubro de 1831, "O Universal"19 tomou como modelo a crise romana no período imperial para alertar a população para instalação do caos caso houvesse a continuidade do conflito. Novamente a preocupação com os caminhos que a representação da liberdade poderia tomar levou "O Universal"20, em 28 de dezembro de 1831, a escrever um editorial de primeira página no qual havia especialmente $o$ cuidado para que os conflitos ocorridos em outras províncias não chegassem até a província mineira. Entendia o texto que mesmo com a vivência do excesso de tributos com a Corte Portuguesa, mesmo a presença do governo considerado despótico de D. Pedro I, mesmo a corrupção que se alastrou, nada era pior que a anarquia. A anarquia tendia a fazer desaparecer a nação, ainda que ocorresse a tentativa de ser sufocada pelos esforços dos que "[...] amam a bem entendida liberdade" ${ }^{21}$.

É importante destacar que Minas Gerais também sentiu os movimentos sociais na Regência com a "Revolta do Ano da Fumaça" em 1833, um movimento sob a liderança de conservadores que eclodiu na província na tentativa de destituir o governo local. A vitória do governo liberal moderado reforçou ainda mais o discurso cauteloso, a bandeira da liberdade foi menos utilizada, substituída muito pelo discurso em favor do patriotismo, pela legalidade, pela justiça. Ao discutir sobre liberdade, o uso de expressões como "ordem", "prudência", "propriedade" e "razão" estavam sempre presentes.
A cautela com o termo liberdade seguiu ao longo dos anos regenciais, retirando seu sentido revolucionário. Na regência de Araújo Lima essa tendência da imprensa em preservar a ordem seria, o que não poderia ser diferente, referendada especialmente em jornais de oposição aos liberais moderados. "O Unitário"22 fez dura crítica à Assembleia Provincial, no dia 31 de março de 1841, citando os liberais da família Marinho, Ottoni e Antão, como opositores à monarquia constitucional, apoiadores da república e da democracia. $\mathrm{O}$ jornal entendia que a "liberdade bem entendida" não aceitava o homem sem limites, que respeitasse as leis e a ordem, e que estando no governo respeitariam o dinheiro público e a propriedade.

\section{O Segundo Reinado e as novas formas de sentir a liberdade: menos elucubrações, mais praticidade}

Com a antecipação da maioridade de D. Pedro II e ascensão dos liberais ao poder, embora por pouco tempo, o discurso destes em favor da monarquia que chamavam de representativa era natural. Ainda no segundo semestre de 1841, quando este partido perdeu o ministério e se tornou oposição, continuou mantendo as publicações com o discurso de ordem e estabilidade, o que podia ser visto na comemoração do $16^{\circ}$ aniversário do imperador e considerando que, segundo a publicação de 03 de dezembro de 1841 do jornal "O Universal", "[...] a liberdade sem ordem é o mais hediondo estado da sociedade" 23 e complementa citando que "[...] existe a monarquia representativa que tempera os excessos da liberdade [...] "24. O partido Conservador, já no governo, em 23 de fevereiro de 1842, corroborava com essas ideias: "[ ...] os mineiros só querem ordem e aquela liberdade, que deve resultar do respeito e devida obediência às leis e autoridades constituídas" 25 .

Gradativamente, no final do período Regencial, a liberdade já sofria um deslocamento do plano filosófico, que daria um caráter de ação política e de diversas interpretações, mas causadora de desordens de toda espécie, para uma relação onde se poderia pensar em liberdade 
voltada para uma estabilidade duradoura e para o desenvolvimento econômico. A liberdade deixaria de ser um elemento de contrários, como foi no Primeiro Reinado (liberdade $\mathrm{x}$ despotismo) e no período Regencial (liberdade $\mathrm{x}$ anarquia) para ser um modelo conciliatório (liberdade e progresso). Portanto, a importância do debate em torno da liberdade perdeu fôlego, não só com menor espaço para discutir seu sentido como também o próprio sentido de liberdade tomou outros rumos nesse novo modelo de imprensa.

O "Correio de Minas" ${ }^{26}$, em 07 de agosto de 1842 , já sinalizava essa nova interpretação dada para a representação da liberdade que já vinha sendo construída no final do período regencial. Para o jornal, durante a luta pela independência, houve a exclusividade do elemento político como produtor de ideias, estando a palavra liberdade na ordem do dia. Seu uso tanto era útil para entusiasmar e dar vigor à construção de uma nova nação quanto alimentava a esperança em um futuro promissor. No entanto, com o aprendizado social, com as dificuldades vividas, com as releituras feitas, "A época de entusiasmo sucede a da reflexão"27. O saber, o talento e a probidade é que deveriam guiar o homem público. Seria dentro das tradições religiosas, do desenvolvimento industrial e das ciências que a liberdade deveria ser guiada e não em pensamentos que não tinham fundamentação na vida moderna: "É a estes elementos que os estados modernos devem a sua prosperidade, fruto de séculos e de inefáveis trabalhos de inteligência: sem eles a liberdade é uma palavra vaga, que só serve à ambição dos especuladores políticos"28. Ou seja, a liberdade assumia um sentido pragmático, estava diretamente relacionada com o progresso e os benefícios que tanto o desenvolvimento no campo da ciência como no da indústria poderiam oferecer. Para o jornal "Correio de Minas", o debate em torno dos limites da liberdade, seu sentido filosófico, sua relação com a política, nada mais conduzia senão à anarquia, pois seu papel de consolidar uma monarquia representativa e conter o despotismo já estava cumprido.

Assim, o conceito de liberdade assumiu no referido período um papel prático, não mais elucubrações ou idealizações de governos, mas apontando para sua realização a partir de ações na vida cotidiana, como pensar em um sistema eleitoral mais eficiente ou abusos políticos dentro da esfera provincial, denunciando o mau uso do dinheiro público ou o empreguismo realizados pelos presidentes de província.

Esse contexto favoreceu muito a penetração de uma perspectiva econômica para a vida pública. Houve a influência de pensadores europeus ligados à economia política, como Michel Chevalier e Charles Dunoyer, que procuravam defender a indústria como único sistema que propicia o homem moderno exercer suas faculdades sem o temor de ser vitimado pela força ou pela guerra. $\mathrm{Na}$ indústria o homem busca a paz, ou seja, a vida material é que leva o ser humano à liberdade. Em um debate literário entre os deputados provinciais reproduzido em 15 de janeiro de 1855 no jornal "Bom Senso"22, o legislador Agostinho José Ferreira Bretas expõe esse pensamento, citando Chevalier e Dunoyer, afirmando que a indústria antecedeu a liberdade, visto que

Os homens procuram desde muitos séculos a liberdade e a liberdade tem de ser para os homens um rico presente do regime industrial [...] está tão ligado a indústria à liberdade que já se tem lido que o consumo do ferro em um país qualquer revela até certo ponto o grau de civilização a que ele tem chegado"30

O discurso do lema "liberdade e progresso" é constantemente reiterado: "A liberdade e o progresso são duas entidades tão intimamente ligadas que se pode dizer uma complemente da outra $[\ldots]^{\prime \prime 31}$. Entendendo aqui que o progresso, ainda que mínimo no Brasil, somente foi conseguido pela liberdade conquistada ao longo de séculos, e a ampliação dessa liberdade está diretamente relacionada com avanços tanto material como espiritual. Até mesmo o partido Liberal assim anunciava, em 28 de setembro de 1866, como o "responsável' pela “[...] causa da liberdade confiada aos homens do progresso" 32 . 


\section{A liberdade assumindo um formato mineiro}

Paralelamente a esse debate, a liberdade assumiria um caráter regional em Minas Gerais. Diante do espaço econômico perdido ao longo do Segundo Reinado, especialmente com a produção cafeeira no Rio de Janeiro e depois São Paulo, a representação da liberdade na província passou a ter como referência o passado mineiro.

Vincular a identidade mineira como uma liberdade a partir de uma imagem nostálgica construída nesse período é o que Raoul Girardet (1987) considera que, ao evocar um passado que já não existe mais. Há uma oposição entre o tempo de outrora e o do presente. Uma necessidade de buscar na grandeza de um tempo passado diante de um tempo presente decadente, degradado e em desordem. É uma exaltação da grandeza do tempo de ontem com o objetivo de garantir a ressurreição, a glória perdida, uma nobreza que cabe redescobrir. Sendo ação mobilizadora, carregava a imagem de um passado que serve como modelo, valor que serve de exemplo. Como mito político, é uma evocação nostálgica, mas que pertence também à esperança e cria uma expectativa do seu retorno. É uma representação do passado que desemboca em uma projeção futura.

O saudosismo do tempo de antes povoou o discurso da imprensa mineira desse período, segundo matéria de 21 de março de 1874 do jornal "O Noticiador de Minas": "Houve uma época em que teve a província de Minas sim período de felicidades"33. Bem como a ação mobilizadora de um reerguimento a partir do passado de glórias, a qual é citada no "Diário de Minas" de 27 de junho de 1874 "[...] e a infeliz província de Minas verá renascer em seus filhos o vigor antigo para utilizar essas riquezas que doeram-lhe os pés, mas que agora lhe são inúteis" ${ }^{34}$. Foi no arquétipo do "espírito mineiro", carregado nas lutas do passado de glórias que a imprensa passou a identificar liberdade com mineiridade. A oposição a todo tipo de despotismo tornou-se uma referência por sua trajetória de lutas, conforme mostra o seguinte trecho do jornal
"O Liberal de Minas" de $1^{\circ}$ de agosto de 1868: "A província de Minas não pode esquecer o seu passado. Será, como sempre, pela liberdade [...]"35. Uma Minas Gerais que tinha na Conjura uma de suas referências, talvez a principal, mas não única e que carrega sua importância no conjunto desse sentimento de liberdade.

É uma representação que difere daquelas produzidas a partir da construção da ordem monárquica, pois se fundamentava na proximidade maior de uma realidade específica de Minas Gerais. Ainda que não se possa dar a dimensão exata, como qualquer imagem, há um mínimo de identidade entre os heróis mineiros e a população da província, diferente da liberdade projetada e inculcada nas primeiras décadas do império. Segundo o olhar da imprensa de 1867, cada mineiro incorporava e se sentia como extensão dos defensores da liberdade, daí, por exemplo, vir com constância o nome dos conjurados no plural, como sendo uma construção coletiva da população, feitas por quem viveu no passado e ainda incorporados nos que viviam o período presente: “[...] é de se esperar que os filhos da heroica terra de Tiradentes, dos Cláudios, Alvarengas, Freires de Andrade e outros ilustres mártires da independência e liberdade do Brasil, acudam pressurosos ao chamado do governo [...]"36 ou "[...] Gonzagas, Alvarengas, Cláudios, Rolins ...A pátria dos grandes homens é sem dúvida Minas" ${ }^{\prime 37}$.

Sendo a província considerada o berço e guardiã da liberdade, havia uma condução a uma sacralização da terra mineira. $\mathrm{O}$ gesto heroico, o ato nobre, um povo que já tinha definido seu papel frente à nação como referência de luta em prol da liberdade, conforme matéria de 06 de outubro de 1868, do periódico "O Noticiador de Minas": “ [...] e a província de Minas não cerrará seus ouvidos ao nobre apelo do governo [...] para que o povo mineiro não perca na história o lugar assinado que já conquistou e lhe convém [...]Eia, pois, avante, briosos filhos das montanhas"38. É um clamor que, além de construir seu tempo ficção, de criar um sistema de explicação, também tem sua mensagem mobilizadora encarnada na figura de Tiradentes e seu martírio. O 21 de Abril foi adotado pelos 
periódicos liberais e conservadores entre os anos de 1860 e 1880.

A liberdade em torno de um passado heroico, um povo que se fez como referência e cultivador de suas práticas, dentro dos limites legais defendida pelos liberais e conservadores vai ao encontro dos interesses políticos dos partidos que dão sustentação à monarquia. Mesmo não considerando Conservadores e Liberais "farinha do mesmo saco", o respeito à liberdade nos limites legais por esses partidos passava a ser compartilhado a partir dos anos de 1860. Havia em ambos, nesse momento, a aceitação da competição partidária dentro das normas institucionais, que inseria o uso do termo liberdade dentro desses limites, assegurando que a utilização da expressão daria a garantia de que não estimularia os excessos, e, consequentemente, as rupturas. Quando caíram os Liberais em 16 de julho de 1868, o "Constitucional" em sua edição n ${ }^{\circ} 111$ : "Queremos a ordem, queremos a liberdade, mas nos limites da lei”39. Desse modo, o vínculo entre liberdade e voto é uma construção permanente na proposta partidária, como fez o jornal " $O$ Conservador de Minas", em 18 de fevereiro de 1870, ao chamar a atenção sobre o processo eleitoral do senado realizado naquele ano, destacando que “... pela primeira vez, talvez, tem Minas presenciado a liberdade no pleito eleitoral..." ${ }^{40}$. Ou seja, para conservadores e liberais, quando se pensava em mudanças políticas, a proposta fogia a tendências extremas.

Porém, no final dos anos 1860, a causa republicana voltou também seu olhar para aliberdade construída na "pátria mineira", mas com propostas distantes das ações pensadas pelos modelos liberal/ conservador. A tradição heroica mineira passou a ser exposta na imprensa pelos defensores da república para confrontar com a monarquia. $\mathrm{O}$ jornal "Colombo" iniciou esse ataque colocando em oposição o espírito de liberdade encarnada pelo povo mineiro com os abusos da monarquia, citando em 26 de outubro de 1873: "Minas, a pátria de Tiradentes, o berço desses heróis que sangraram no patíbulo no exílio e no cárcere a ideia redentora da liberdade, é hoje infamada pela monarquia" ${ }^{41}$. Para a imprensa que combatia a monarquia,
Minas Gerais já tinha como componente natural um espírito republicano. Ao criar um sentimento de identidade e comunhão entre os mineiros, o discurso em torno dos seus habitantes dotados de um espírito de liberdade serviu como representação mobilizadora para se fazer presente na luta pelo fim da monarquia, representando uma continuidade da conduta dos antepassados.

Os jornais republicanos de Minas Gerais chegaram ao final da década de 1880 fazendo dos mineiros um exemplo a ser seguido pelo restante do Brasil. Assim, de acordo com a província reassumia triunfante o papel perdido há décadas, ressurgindo como grande inspiradora e guardiã da liberdade nos moldes de uma república fundada em um sentimento que considerado nato, sempre cultuado pelos mineiros. Agora líder, inclusive das duas outras províncias que ganharam força no sudeste, Rio de Janeiro e São Paulo, Minas Gerais voltava a ter o papel glorioso perdido no tempo, o que se verifica nessa informação de 23 de janeiro de 1889, do jornal "O Movimento": "Nossa província, lembrada de suas lutas de outrora que sempre visaram o alvo radiante da liberdade quer mostrar no terreno da ação o valor de suas convicções..." ${ }^{* 2}$.

Por sua vez, Liberais e Conservadores silenciavam-se diante de um sentimento de liberdade que já não era mais deles, pois foi adotado por quem combatia a sua base institucional. Nos anos que antecedem o 15 de novembro, os jornais liberais e conservadores, ignoravam o dia 21 de abril, tão comemorado, sinalizando que é uma data que não mais lhes pertencia. No máximo, procuravam discutir reformas, como o federalismo, sem encontrar um consenso, mencionando, por exemplo, o jornal "O Liberal Mineiro": "É a federação das províncias a esperança atual do partido liberal" ${ }^{33}$ ou o "Vinte de Agosto": "a federação, que é um lobo que devoraria a monarquia, opõe-se aos nossos costumes [conservadores]..."44

Em 30 de março de 1881, o jornal liberal "A Atualidade" discutia sobre os símbolos da bandeira imperial : "[...] ocupa no grande convívio das velhas nacionalidades um lugar de honra, desfraldando a bandeira auriverde, que simboliza - Liberdade e Ordem - Paz, pelo Império da Lei - progresso, pelo 
trabalho e pela liberdade" ${ }^{\prime 5}$. Mal sabiam, ou bem sabiam, que o lema liberal "Liberdade e Progresso" somado ao lema Conservador "Liberdade e Ordem", ambos exaustivamente utilizados na segunda metade do século XIX, iriam compor alguns anos depois, com um novo jogo de palavras, rumos republicanos para o Brasil.

\section{Conclusão}

Houve, no Primeiro Reinado, uma grande preocupação da imprensa mineira em estabelecer fronteiras e limites para a representação em torno do conceito de liberdade. Próximo ao projeto monárquico, seus princípios se fundem com o projeto liberal, onde o limite é a Constituição. Seus excessos são rotulados de "liberdade não entendida". Porém, apesar da defesa da liberdade na esfera legal, tudo indica que a censura imposta por D. Pedro I levava a manifestações por parte da imprensa, que usavam do debate em torno da liberdade como importante ferramenta para questionar, mesmo por analogia, os abusos do governo no Primeiro Reinado.

A abdicação de D. Pedro I transfere o papel libertador ao filho, mantendo o discurso que atrela lei e ordem à liberdade. Nos primeiros momentos da regência, abre-se a discussão em torno de uma maior liberdade para o legislativo, mas logo contido o debate como resultado do terror a movimentos que poderiam por em risco a ordem vigente. Tendo os liberais moderados à frente do governo na sua maior parte, a consequência é um deslocamento, ao longo do Período Regencial, a abordar com menor intensidade temas sobre liberdade. E quando a liberdade foi colocada em pauta, o discurso se voltou no combate ao anarquismo, enfatizando o embate entre razão e paixão, moderação e radicalismo, colocando para segundo plano o temor do despotismo tão evidenciado no período pedrino.

Com o novo imperador, em 1840, novo sentido vai ser dado à representação da liberdade relacionada com o progresso, assumindo um caráter mais pragmático. Ou seja, uma busca de liberdade mediante benefícios materiais e não por idealizações como ocorria nas décadas anteriores. Coexistindo com esse discurso ligando liberdade, ordem e progresso, em Minas Gerais surgiu uma representação de liberdade que se identificou com os mineiros. Havia, na evocação do passado, o reencontro de um "espírito mineiro", que se tornou referência pelas lutas heroicas do passado em prol da liberdade, assumindo Minas Gerais a condição de ser sua principal guardiã, visando reestabelecer a importância da província no Brasil. Assim, criouse em torno desse mito a expectativa do retorno grandioso de Minas no cenário nacional. Mito mobilizador, atendendo aos interesses dos partidos ligados à monarquia, pois é uma liberdade que atua dentro dos limites legais. No entanto, o movimento republicano também se apropriou dessa imagem e reconstruiu o mito libertário mineiro como instrumento de adesão e ação para derrubada da monarquia, retomando uma aliança entre o Brasil e Minas Gerais, perdida nos anos de 1840.

\section{Notas}

Os periódicos citados neste estudo foram consultados no Arquivo Público Mineiro (APM).

1 O Universal, ed. 256, 05/03/1825. In: APM

2 O Universal, ed. 01, 16/07/1827. In. APM.

3 O Universal, ed. 280, 30/04/1827. In. APM.

4 O Amigo da Verdade, ed. 07, 29/05/1829. In APM.

$5 \mathrm{O}$ Telégrafo, ed. 171, 28/12/1830. In. APM.

$6 \mathrm{O}$ Telégrafo, ed. 171, 28/12/1830. In. APM.

7 O Amigo da Verdade, ed. 07, 29/05/1829. In APM.

8 O Amigo da Verdade, ed. 01, 08/05/1829. In. APM.

9 O Universal, ed. 357, 26/10/1829. In APM.

10 O Universal, ed. 61, 03/12/1827. In APM.

11 O Universal, ed. 601, 01/06/1831. In APM.

12 O Universal, ed. 585, 22/04/1831. In. APM.

13 O Universal, ed. 589, 02/05/1831. In. APM.

14 O Universal, ed. 584, 20/04/1831. In. APM.

15 O Universal, ed. 581, 13/04/1831. In. APM.

16 O Universal, ed. 604, 08/06/1831. In. APM.

17 O Universal, ed. 585, 02/04/1831. In. APM.

18 O Universal, ed. 644, 09/09/1831. In. APM.

19 O Universal, ed. 664, 26/10/1831. In. APM. 
20 O Universal, ed. 690, 28/12/1831. In. APM.

21 O Universal, ed. 690, 28/12/1831. In. APM

22 O Unitário, ed. 01, 31/03/1841. In APM.

23 O Universal, ed. 128, 03/12/1841. In. APM.

24 O Universal, ed. 128, 03/12/1841. In. APM.

25 O Correio de Minas, ed. 23, 23/02/1842. In APM.

26 O Correio de Minas, ed. 73, 07/08/1842. In APM.

27 O Correio de Minas, ed. 73, 07/08/1842. In APM.

28 O Correio de Minas, ed. 73, 07/08/1842. In APM.

29 Bom Senso, ed. 288, 15/01/1855. In APM.

30 Bom Senso, ed. 288, 15/01/1855. In APM.

31 Diário de Minas, ed. 72, 06/09/1866. In APM.

32 Diário de Minas, ed. 88, 28/09/1866. In APM.

33 O Noticiador de Minas, ed. 225, 21/03/1874. In. APM.

34 Diário de Minas, ed. 277, 27/06/1874. In. APM.

35 O Liberal de Minas, ed. 61. 01/08/1868. In APM.

36 Diário de Minas, ed. 223, 01/05/1867. In APM.

37 Diário de Minas, ed. 214, 13/04/1867. In APM.

38 O Noticiador de Minas, ed. 19, 06/10/1868. In APM.

39 Constitucional, ed. 111, 26/10/1868. In APM.

40 O Conservador de Minas, ed. 02, 18/02/1870. In APM.

41 Colombo, ed. 42, 26/10/1873. In APM.

42 O Movimento, ed. 242, 23/01/1889. In APM.

43 O Liberal Mineiro, ed. 278, 24/09/1885. In APM

44 Vinte de Agosto, ed. 03, 20/09/1885. In APM.

45 A Atualidade, ed. 32, 30/03/1881. In APM.

\section{Referências}

BOSI, Alfredo. Dialética da colonização. São Paulo: Cia das Letras, 1998.

CARVALHO, Kátia. Imprensa e informação no Brasil, século XIX. Revista Ciência da informação, vol. 25, nº3, 1996.http://revista.ibict.br/ciinf/index. php/ciinf/abou/contato. Acesso em 05.03.2013.
GIRARDET, Raoul. Mitos e mitologias políticas. São Paulo: Companhia das Letras, 1987.

GUIMARÃES, Lúcia Maria Paschoal. Liberalismo moderado: postulados ideológicos e práticas políticas no período Regencial (1831-1837). In O liberalismo no Brasil imperial: origens, conceitos e práticas. GUIMARÃES, Lúcia Maria Paschoal (org.) PRADO, Maria Emília (org.) Rio de Janeiro: REVAN: UERJ, 2001. p. 103-126.

MOREIRA, Luciano da Silva. Imprensa e política: espaço público e cultura política na província de Minas Gerais (1828-1842). 272 f. Dissertação (mestrado em História e culturas políticas). Universidade Federal de Minas Gerais, Belo Horizonte, 2006.

MOREL, Marco. As transformações dos espaços públicos: imprensa, atores políticos e sociabilidades na cidade imperial (1820-1840). São Paulo: HUCITEC, 2005.

NEVES, Lúcia M. Bastos P. Neves. Liberalismo político no Brasil: ideias, representações e práticas (1820-1823). In O liberalismo no Brasil imperial: origens, conceitos e práticas. GUIMARÃES, Lúcia Maria Paschoal. PRADO, Maria Emília. (orgs.) Rio de Janeiro: REVAN: UERJ, 2001. p. 73-101.

RIBEIRO, Gladys Sabina. A liberdade em construção: identidade nacional e conflitos antilusitanos no Primeiro Reinado. 315 f. Tese (doutorado em História). Universidade Estadual de Campinas. Campinas, 1997.

SILVA, Wlamir. Liberais e povo: a construção da hegemonia liberal-moderada na província de Minas Gerais (1830-1834). São Paulo: Aderardo \& Rothschild; Belo Horizonte: Fapemig, 2009. 